\title{
IMPLANTAÇÃO DO PROGRAMA SAÚDE DA FAMÍLIA NO ESTADO DE RORAIMA
}

\author{
Claúdia Monteiro de Souza ${ }^{1}$ \\ Maria Verônica Patrício Gianluppr
}

\begin{abstract}
O Brasil é um país de dimensões continentais e possui um dos maiores índices de desigualdade sócio-econômica do mundo. Conforme dados do Relatório sobre Desenvolvimento Humano de 1996, no Brasil, a proporção de pobres é mais elevada nas regiões Nordeste ( $46 \%$ ) e Norte ( $43 \%$ ).

Localizado a Noroeste da Região Norte, com
\end{abstract} uma área de $225.116 \mathrm{Km}^{2}$, o Estado de Roraima passou da condição de território para a de estado Na Universidade Federal de Roraima, a única do estado, somente o curso de medicina é ofertado, e formou sua primeira turma com 9 alunos em 1999, já o curso de enfermagem ainda não é oferecido pela instituição.

em 1988. Apresenta clima equatorial a Oeste e tropical a Leste. Sua população é de aproximadamente 266.922 habitantes, com uma densidade de $1,15 \mathrm{hab} . / \mathrm{Km}^{2}$. Tem como fronteiras nacionais os Estados do Amazonas e Pará, e internacionais a Venezuela e a República Cooperativista da Guiana (ex Guiana Inglesa).

Com apenas 15 municípios, Roraima é o estado menos populoso e o de menor densidade demográfica do Brasil. No entanto, concentra a terceira maior população indígena do país, que representa aproximadamente $14 \%$ da população estadual e que ocupa mais da metade das terras do estado, em áreas demarcadas, por demarcar e em litígio.

A Taxa Média de Crescimento da População no Estado de Roraima $(2,6)$ é quase o dobro da Taxa do Brasil $(1,4)$. Apresenta, por um lado, a Taxa de Fecundidade total mais alta do país e elevada Taxa Bruta de Natalidade $(25,7)$, igualada a da Região Nordeste $(25,7)$, além de ter a Taxa Bruta de Mortalidade mais baixa do país e das suas regiões. Por outro lado, sistemática migração de pessoas de outros estados, calcula-se que em torno de 9.000 pessoas chegaram ao estado no primeiro trimestre de 1999.

A participação do estado no PIB é de 0,14\%, com uma economia baseada na agricultura basicamente de gêneros alimentícios para consumo local -, na pecuária - essencialmente bovina e de corte -, na mineração - principalmente de ouro e diamantes- e indústria - produz apenas para o mercado local. O turismo ecológico vem sendo incentivado principalmente na região da Floresta Amazônica e nas serras da fronteira com a Venezuela.

A economia de Roraima é incipiente, em virtude, sobretudo, da precariedade do fornecimento de energia elétrica e da rede viária. O sistema de transporte foi melhorado com a abertura da BR 174 no final da década de 1970, mas cujo asfaltamento só foi completado em novembro de 1998. Com 970 $\mathrm{Km}$, a rodovia, que começa em Manaus (AM) e termina na fronteira com a Venezuela, é a única ligação terrestre com o resto do país.

Em Roraima o sistema de atendimento básico à saúde conta com um hospital geral, uma maternidade, um hemocentro, um laboratório central, centro de imagens e onze centros de saúde localizados na capital, Boa Vista. No interior possui cinco unidades mistas e postos de saúde, localizados nas sedes dos municípios e nas áreas indígenas.

\footnotetext{
${ }^{1}$ Enfermeira. Coordenadora Estadual do Programa de Agentes Comunitários de Saúde (PACS) e do Programa de Saúde da Família (PSF) de Roraima. Cursa Especialização em Saúde Pública da ENSP/ FIOCRUZ.

2 Assistente Social. Assessora da Coordenação do PACS e do PSF de Roraima. Cursa Especialização em Saúde Pública da ENSP/FIOCRUZ.
} 
O sistema de saúde está estruturado segundo o modelo do PAl adotado por São Paulo, no qual cooperativas mantidas pelo estado gerenciam os recursos humanos. Além disso, atuam também no sistema profissionais de saúde com vínculo federal, do antigo território ou transferidos de outros estados.

Para se ter uma idéia da situação da saúde no estado, Roraima apresenta taxas de mortalidade infantil de 21,2 por 1000 nascidos vivos e mortalidade geral de 41,1 por 10.000 habitantes. No entanto, elevadas taxas de crescimento populacional têm obrigado o Sistema de Saúde Estadual a dar respostas efetivas às mudanças demográficas e epidemiológicas decorrentes da realidade, que vem criando condições favoráveis para o aumento da incidência e prevalência de variadas doenças (Malária, Hanseníase, Tuberculose).

Todos esses fatores levam o estado a conviver com graves problemas, que atingem sobremaneira todos os níveis e camadas sociais, não só pela exaustão da estrutura de atendimento á saúde, mas também em decorrência da introdução de diversas culturas, trazidas por populações de todas as regiões do país.

O estado vem investindo em programas e ações de forma a atender a população, priorizando famílias carentes, a fim de que recebam apoio, orientação, atendimentos e assistência médica. Os Programas de Agentes Comunitários de Saúde e Saúde Família são estratégias fundamentais para se alcançar esses objetivos, uma vez que recebem financiamento do Ministério da Saúde, repasse de incentivo fundo a fundo e reconstituem a estrutura da Atenção Básica à Saúde.

Ao assumirmos a Coordenação Estadual do PACS, no final do mês de julho de 1998, encontramos o programa implantado em apenas dois municípios, Caracaraí e Boa Vista, num total de 47 Agentes Comunitários, o que representava $7,6 \%$ da cobertua.

No município de Caracaraí, o programa estava desativado desde o início de março de 1998, por falta de um Enfermeiro. O município de Boa Vista estava com apenas $40,2 \%$ de sua capacidade produtiva, com 37 dos 92 Agentes que teria direito em atividade.

Após avaliação do quadro, iniciamos processo de discussão com os dois municípios na tentativa de recuperar o espaço conseguido e recuperar a credibilidade do programa. Conseguimos nos meses de setembro e outubro ampliar e reestruturar o programa em Boa Vista, passando de 37 para 142 Agentes, com a realização de processo seletivo e dos primeiros treinamentos. Neste período conseguimos também a implementação, ampliação e reestruturação do PACS do município de Caracaraí, reestruturando a coordenação e passando de 0 para 17 Agentes.

Em paralelo a esse processo, realizamos a sensibilização dos outros 06 municípios que já estavam habilitados na Gestão Plena de Atenção Básica. Foram realizadas várias reuniões para sensibilização, estruturação e organização das Secretarias Municipais de Saúde com relação a contratação dos profissionais enfermeiro e médico. Aproveitamos para implementar discussões acerca do Programa de Saúde da Família.

No período de maio a dezembro de 1999 iniciamos a implantação do Programa de Agentes Comunitários de Saúde em mais 6 (seis) municípios e de 07 equipes do Programa de Saúde da Família, sendo 5 equipes na capital e 02 no município de Alto Alegre. Se no final de 1998 conseguimos ampliar o número de Agentes para 144 - aumentando a cobertura para $24,28 \%$-, no primeiro semestre de 1999 aumentamos o número de Agentes Comunitários para 220, perfazendo $37 \%$ da necessidade geral do estado de Roraima.

Esse impulso deu-se com as parcerias firmadas com os gestores das localidades de Caracaraí, Boa Vista, Alto Alegre, Iracema, Pacaraima, Rorainópolis e São Luiz, que iniciaram sua atuação no mês de julho e Mucajaí que iniciou sua atuação no mês dezembro de 1999.

As discussões com os Secretários Municipais de saúde que deram início ao processo de implantação do Programa de Saúde da Família no Estado de Roraima, foram realizadas a partir de março de 1999, numa tentativa de conscientizar os gestores da importância de se aderir a essa estratégia. Várias foram as dificuldades encontradas, dentre elas destacaram-se:

a) Estruturas municipais incipientes, em função da imaturidade administrativa do Estado, acarretando sérios entraves a organização administrativa dos municípios, que ainda se mostram muito dependentes, como acontecia na estrutura de território federal. Tal política acarretou seqüelas, como 
a insensibilidade dos gestores municipais para a importância da adesão ao Programa de Saúde da Família, que seria um dos pilares para a organização do sistema de saúde.

b) Outro ponto dificultador está na carência de contratação de mão-de-obra especializada, com profissionais de nível superior, médicos e enfermeiros, seja por carência de profissionais interessados ou pelos salários pouco competitivos oferecidos. Na Universidade Federal de Roraima, a única do estado, somente o curso de medicina é ofertado, e formou sua primeira turma com 9 alunos em 1999, já o curso de enfermagem ainda não é oferecido pela instituição.

Até o presente momento, o PSF está implantado em dois municípios, sendo que o primeiro a aderir a essa estratégia foi o município de Boa Vista (capital), que concentra $64 \%$ da população do estado.

O processo de implantação do Programa de Saúde da Família, vem se desenvolvendo de forma lenta. No entanto, apesar de ainda contarmos com reduzido apoio de alguns gestores municipais, notamos que em alguns municípios os gestores estão bem conscientes da importância de aderir a estratégia de Saúde da Família. O esforço e a vontade de fazer da Coordenação Estadual, aos poucos vem fazendo com que adesão desses parceiros se intensifique, para efetivarmos a implantação de novo modelo de assistência básica na Saúde em Roraima.

A evolução dos dois programas foi conquistada através do trabalho corpo a corpo da Coordenação Estadual com os Secretários municipais. Este avanço impôs novos desafios e tarefas à Coordenação, tais como o aumento dos deslocamentos geográficos para assessorar os municípios, para realizar supervisões periódicas e a implantação do PACS e do PSF, nos demais municípios do estado.

A importância da continuidade do Processo de Descentralização, com a implantação do SUS e dos programas que o constituem, nos leva a ampliar nossos esforços para apoiar e colaborar na estruturação dos municípios, para que esses possam assumir as Ações Básicas de Saúde, de maneira eqüanime, integral e universal. Neste sentido, o nosso trabalho só começou. 